\title{
Pediatric food allergy and mucosal tolerance
}

\author{
AM Scurlock ${ }^{1}$, BP Vickery ${ }^{2}$, JO'B Hourihane ${ }^{3}$ and AW Burks ${ }^{2}$
}

\begin{abstract}
The gastrointestinal (GI) mucosal immune response is characterized by an intricate balance between host defense and immunoregulation. A principal element of this normal response is acquisition of oral tolerance. Aberrations in oral tolerance induction can lead to food allergy, an increasingly prevalent disorder that causes significant medical and psychosocial stressors for patients and families. At present there is no definitive therapy for food allergy and the mainstays of treatment are allergen avoidance, nutritional support, and ready access to emergency medications. Significant progress toward an active therapy for food allergy has been made with the advent of novel therapies such as oral immunotherapy (OIT) and sublingual immunotherapy (SLIT), which modulate the GI mucosal immune response with the goal of promoting oral tolerance. In this review, we will examine the mechanisms of oral tolerance induction and its relation to food allergy and explore novel immunotherapeutic strategies for treatment and prevention of food allergy.
\end{abstract}

\section{INTRODUCTION}

The hallmark of the mucosal immune response lies in its ability to balance reciprocal, site-specific immunoprotective and immunoregulatory responses to maintain diverse physiologic functions such as digestion, respiration, reproduction, and olfaction. Nowhere is this immunologic duality better evidenced than in the mucosal immune response of the gastrointestinal (GI) tract, where development of oral tolerance to ingested foods and commensal bacteria is the norm. Aberrations in the mucosal immune response and oral tolerance induction can lead to immune-mediated GI diseases such as food hypersensitivity. Great interest has developed recently in targeting the mechanisms of oral tolerance induction to prevent and treat food hypersensitivity, providing hope for a definitive intervention for this disorder. In this review, we will focus on the anatomy of the GI mucosal immune response and oral tolerance induction; the aberrations in this response that lead to food hypersensitivity; and novel therapeutic approaches to target mucosal immune responses and promote oral tolerance induction.

\section{FOOD ALLERGY: A DISORDER OF ABERRANT MUCOSAL TOLERANCE}

Food allergy is an increasingly prevalent disorder with potentially life-threatening complications, requiring affected individuals and families to make life-altering modifications in dietary habits and psychosocial interactions. At present, the standard of care includes strict dietary elimination of the implicated allergen and ready access to injectable epinephrine (adrenaline); however, there are no active, definitive therapeutic options for food allergic patients. Because of the need for strict elimination diets, difficulty interpreting food labels, ${ }^{1,2}$ the high risk of accidental exposures, ${ }^{3}$ and the threat of severe or fatal reactions, ${ }^{4,5}$ diagnosis of food allergy can be life-altering for patients and families, resulting in significant anxiety, psychosocial stressors, and reduced healthrelated quality of life. ${ }^{6-10}$

Although the detailed immunologic mechanisms underlying the development of immediate food hypersensitivity are still being fully defined, food allergy appears to be the direct result of a breakdown in the normal development of oral tolerance or breakdown in existing tolerance, resulting in dysregulated T-helper type-2 (Th2) responses and immediate hypersensitivity reactions upon antigen re-exposure. Ineffective induction of regulatory T-cells (Tregs) has been shown to promote the development of food allergy. ${ }^{11-14}$

\section{GI MUCOSAL IMMUNITY AND FOOD ALLERGY}

The GI mucosal immune system has evolved both innate and adaptive components that are adept at inhibiting responses to antigens such as food proteins and commensal bacteria, while mounting immunoprotective responses against pathogenic organisms, in an effort to maintain the primary physiologic function of nutrient absorption. GI mucosal immune responses involve complex interactions between multiple components, including the epithelial barrier and its associated proteins and

\footnotetext{
${ }^{1}$ Pediatric Allergy and Immunology, University of Arkansas for Medical Sciences, Arkansas Children's Hospital Research Institute, Little Rock, Arkansas, USA. 2 Pediatric Allergy and Immunology, Duke University Medical Center, Durham, North Carolina, USA. ${ }^{3}$ University College, Cork, Ireland, USA. Correspondence: AW Burks (Wesley.Burks@duke.edu) 
antibodies, as well as interactions between antigen-presenting cells and T-cells. These interactions are reviewed in full detail elsewhere in this issue; we will therefore focus our discussion on the direct relevance of these interactions in models of food allergy. Food proteins present in the normal diet also have a crucial role in stimulating maturation of the immune system. Mice that are reared on a balanced but protein-free diet have poorly developed gut-associated lymphoid tissue. ${ }^{15}$ Such mice also have low numbers of lymphocytes and reduced levels of circulating $\operatorname{IgG}$ and $\operatorname{IgA}$, as well as cytokine production consistent with Th2 responses.

A principal element of the GI mucosal immune response is acquisition of oral tolerance, defined as specific suppression of cellular or humoral immune responses to an antigen by prior administration of the antigen by the oral route. ${ }^{16,17}$ This response likely evolved as an analog of self-tolerance to prevent hypersensitivity reactions to both ingested exogenous proteins (from food) and commensal bacterial antigens. Mechanisms of oral tolerance induction include clonal anergy/deletion or active suppression. ${ }^{17,18}$ Factors important in oral tolerance induction include age and genetic susceptibility of the host, host commensal flora, route of antigen exposure, and antigen dose and composition, with soluble antigens being more tolerogenic than particulate antigens. ${ }^{19}$ The immunogenic or tolerogenic potential of ingested proteins may also be due to differential uptake of antigens by Peyer's patches or mesenteric lymph nodes, with previous work suggesting antigen transport to the draining mesenteric lymph nodes to be crucial for oral tolerance induction. ${ }^{20,21}$ The potential roles of gastric acid blockers, dietary lipids, antioxidants, and vitamins, that are consumed simultaneously with the sensitizing allergen, in the modulation of mucosal processing of allergen and immune cell activation in relation to oral tolerance induction are also of significant interest and are the subject of ongoing investigation..$^{22}$

Food allergy appears to result from either failure in establishing oral tolerance or a breakdown in existing tolerance, and as effectors of peripheral tolerance, Tregs are likely to be crucially involved. Current data suggest that defective Treg development may have a central role in the development of food allergy and increases in Tregs have been associated with reduced clinical reactivity. ${ }^{11,13,14,23}$ Antigen-specific Tregs suppress immune responses in both lymphoid tissues, where they inhibit generation of effector T-cells, and in target organs, through cytokine production. The transcription factor FOXP3 has been identified as a "master regulator" of the Treg lineages in both mice and humans. ${ }^{24,25}$ Mutations in human FOXP3 are associated with IPEX (Immune Dysregulation Polyendocrinopathy Enteropathy $\mathrm{X}$-linked) Disorder, a fatal X-linked disorder characterized by profound immune dysregulation, severe enteropathy, food allergy, and endocrinopathy. ${ }^{26}$ Interestingly, an IPEX variant has been described in which a deletion in FOXP3 impairs mRNA splicing, protein expression, and in vitro function, resulting in a milder viable phenotype characterized by enteropathy, food allergy, and atopic dermatitis but not endocrinopathy. ${ }^{27}$

Beyer et al. ${ }^{11}$ have shown that in children with non-IgEmediated milk allergy, active GI disease is associated with high
Th2 and low Treg-associated cytokines when compared with controls. Karlsson et al. ${ }^{13}$ determined that children who eventually outgrew their milk allergy had higher levels or circulating CD $4+$ CD25 + Tregs. Shreffler et al. ${ }^{14}$ confirmed that Tregs are important mediators of tolerance in children with milk allergy, showing that subjects who were able to consume heated milk without reaction had a higher percentage of proliferating antigen-specific Tregs than subjects with milk allergy who reacted to heated milk or control subjects without milk allergy.

Recent work using mouse models has also examined the role of Tregs in the genesis of food allergy and in induction of mucosal tolerance. Using a newly developed mouse model of food allergy that uses co-administration of Staphylococcus enterotoxin-B with ovalbumin (OVA) or peanut, Ganeshan et al. ${ }^{28}$ showed that Th2 polarized responses characterized by increased antigen-specific IgE and IgG1 production, clinical reactivity upon allergen challenge, and increased mucosal and systemic eosinophilia, confirming sensitization. In this experimental model, Staphylococcus enterotoxin-B was shown to inhibit the expression of transforming growth factor- $\beta$ and Tregs and promoted responses to peanut antigen by impeding tolerance induction. ${ }^{28}$ Using a series of elegant studies of a mouse model of pulmonary disease, investigators determined that Foxp 3 + Tregs are essential to establish mucosal tolerance and minimize the severity of chronic allergic inflammation. ${ }^{12}$

The role of antigen-presenting cells in shaping the ultimate adaptive immune response has been a subject of much recent investigation. In the context of food allergy, mouse models often use the mucosal adjuvant cholera toxin to promote a Th2 lymphocyte response and IgE production. Recently, investigators determined that co-administration of OVA and cholera toxin to mice resulted in upregulation of Jagged-2 and OX40L on lamina propria dendritic cells resulting in skewing of naïve T-cells in the mesenteric lymph nodes toward a Th2 phenotype..$^{29} \mathrm{OX} 40 \mathrm{~L}$ is a known downstream effector of the epithelial cytokine thymic stromal lymphopoetin, which is a principal element of the Th2 response.

\section{Gl antigen processing and barrier immunity}

The GI tract, including its gut-associated lymphatic tissue, is the largest immunologic organ in the body with an epithelial surface in constant contact with the external environment. ${ }^{17,30}$ After ingestion, dietary proteins undergo digestion by gastric acids and luminal enzymes resulting in reduced protein immunogenicity, apparently by destruction of conformational epitopes. ${ }^{31}$ Factors that disrupt normal digestion and antigen processing have been shown in animal models to result in breakdown of oral tolerance induction. ${ }^{32}$ Dietary antigens are taken up at different sites in the GI tract, including the dendritic cell, microfold cell (M-cell), and epithelial cell routes. ${ }^{17} \mathrm{GI}$ dendritic cells sample the lumen, presenting and processing the antigen to gut-associated lymphatic tissues. Microfold cells are a specialized population of epithelial cells that overlay the Peyer's patches and allow efficient delivery of soluble antigens to sub-epithelial antigen-presenting cells to activate Tregs, usually resulting in immune suppression. Dietary proteins that escape proteolysis 
in the gut can be taken up by intestinal epithelial cells. The epithelial cells may act as non-professional antigen-presenting cells provided they constitutively express major histocompatibility complex class-II molecules on their basolateral membranes and can present antigen to primed T-cells. ${ }^{33}$

Intact barrier function and innate immune mechanisms are a vital part of the mucosal response. ${ }^{34}$ Epithelial junctional complexes, also called adherens junctions (zonula adherens) and tight junctions, regulate gut permeability to bacteria and dietary proteins. The permeability of tight junctions is regulated by changes in gene expression and phosphorylation of tight junction proteins such as occludins, claudins, and JAM$\mathrm{ZO} 1$ proteins. Epithelial barrier function is regulated both by exogenous factors such as alcohol, non-steroidal anti-inflammatory drugs, and pathogen exposure, and by immunologic influences including cytokines, immune cells, and apoptotic pathways. $^{34}$

Food allergies could result from epithelial barrier dysfunction as impaired barrier immunity increases food antigen exposure to the immune system, resulting in antigen sensitization and production of a Th2-predominant allergic response. Interestingly, intestinal permeability was assessed in food allergic infants by examining the lactulose/mannitol ratio in urine, and food allergic infants were noted to have increased intestinal permeability when compared with normal healthy young children. ${ }^{35,36}$ Investigators examined this ratio in children who had been on an allergen-free diet for at least 6 months and determined that intestinal permeability remained increased in food allergic children, despite absence of food allergen stimulation. Further evidence linking GI epithelial barrier dysfunction and food allergy comes from reports of immunosuppressed solid-organ transplant patients who developed food allergy while on calcineurin inhibitors. ${ }^{37-41}$ Initially, investigators assumed this allergy was the result of transfer of sensitized donor lymphocytes; however, it is theorized that medication-induced decreases in cellular ATP levels could alter the integrity of junctional complexes, resulting in increased intestinal permeability. ${ }^{42}$ Forbes et al. ${ }^{43}$ showed increased intestinal permeability and enhanced allergic sensitization in transgenic mice with interleukin-9 (IL-9) overexpression in the enterocytes of the small intestine. These mice showed increased intestinal permeability and developed a significant GI mastocytosis. When mast cells were pharmacologically depleted, epithelial barrier function was re-established in the IL-9 transgenic mice to levels comparable to that in wild-type controls, and this improved barrier function prevented oral antigen sensitization.

\section{TARGETING MUCOSAL TOLERANCE FOR TREATMENT OF FOOD ALLERGY \\ Desensitization vs. tolerance}

Because food allergy results from breakdown of normal oral tolerance induction, novel immunotherapeutic strategies designed to alter the immune system's response to food allergens are under investigation. In the discussion of mucosal immunomodulatory therapies for food allergy, two concepts must be defined.
Desensitization refers to protection from life-threatening anaphylaxis that can be short-term or prolonged with ongoing therapy. Possible mechanisms of desensitization include increased IgG and reduced IgE; in addition to decreased activation and release of inflammatory mediators by mast cells and basophils. By contrast, tolerance refers to active modulation of the immune response to promote Treg development and immunologic skewing away from a Th2 response (Figure 1).

\section{Allergen immunotherapy}

Traditional injection immunotherapy has been shown to be effective for IgE-mediated diseases such as allergic rhinoconjunctivitis, through induction of cellular and humoral mechanisms that result in modulation of disease. ${ }^{44}$ In a study of grass pollen immunotherapy in adults with severe allergic rhinitis, clear clinical efficacy was associated with significant production of the anti-inflammatory cytokine IL-10, elevation of grass pollen-specific IgG4 and IgA, as well as induction of inhibitory antibody activity for histamine release and IgE-facilitated allergen binding to B-cells. ${ }^{45}$ Although it was likely effective in modulating the allergic response, food allergen immunotherapy through the injection route is impractical and unsafe for use in routine clinical settings due to an unacceptably high rate of severe systemic anaphylactic reactions. ${ }^{46,47}$

At present, multiple alternatives to food antigen injection are being evaluated (Table 1). Immunization with mutated peanut protein allergens has shown promising results in mouse models. Through recombinant genetic techniques, Li et al. ${ }^{48,49}$ abrogated the IgE recognition of the major peanut allergens Ara h-1, Ara h-2,

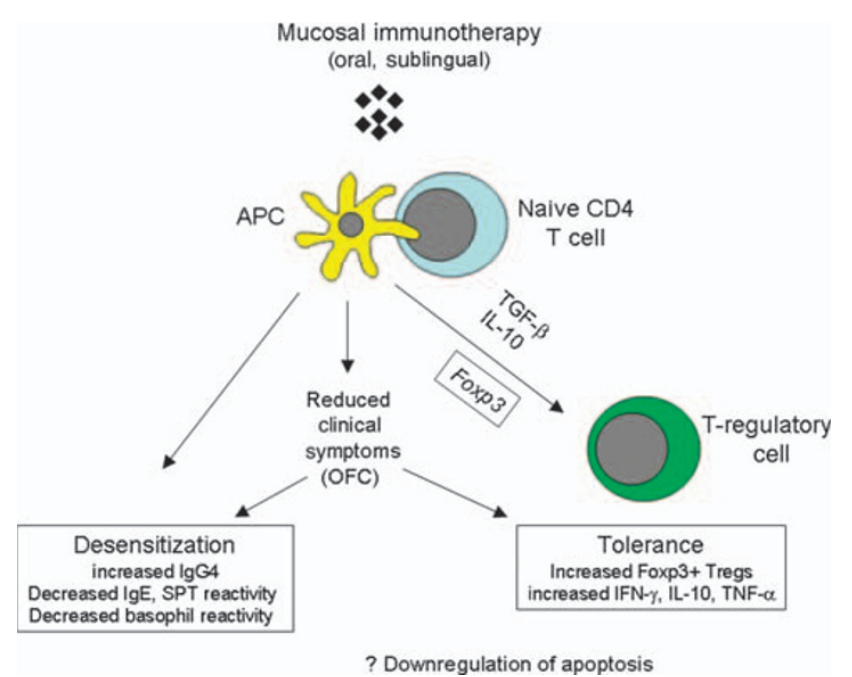

Figure 1 OIT and SLIT result in both desensitization and tolerance induction. Mechanisms of desensitization include increased $\operatorname{lgG}_{4}$ and decreased IgE; reduced skin prick test (SPT) wheal size; decreased basophil reactivity; and decreased mean relative binding when measured by facilitated allergen binding (FAB) inhibition assay. Tolerance induction is associated with increased numbers of FOXP3-expressing Tregs and immunologic skewing away from a Th2 response. Recently, T-cell microarray data showed downregulation of genes in apoptosis pathways in patients on peanut OIT, a novel finding that is the subject of ongoing investigation to define the mechanisms of oral tolerance induction. OIT, oral immunotherapy; SLIT, sublingual immunotherapy; Th2, T-helper-2. 
Table 1 Immunologic effects of selected immunomodulatory therapies for food allergy

\begin{tabular}{|c|c|c|c|c|c|}
\hline Investigators & Therapy & Route & Model & Allergen & Immunologic effects \\
\hline Li et al. & $\begin{array}{l}\text { Traditional } \\
\text { Chinese medicine }\end{array}$ & Oral & Mouse & Peanut & $\begin{array}{l}\text { Protection from anaphylaxis } \\
\text { Reduced PN-specific IgE } \\
\text { Increased IgG2a levels } \\
\text { Reduced Th2 cytokines } \\
\text { Increased IFN- } \gamma \text { by CD8 + T-cells }\end{array}$ \\
\hline Mondoulet et al. & $\begin{array}{l}\text { Epicutaneous } \\
\text { immunotherapy }\end{array}$ & Epicutaneous & Mouse & $\begin{array}{l}\text { Peanut } \\
\text { Egg } \\
\text { Aeroallergens } \\
\text { (dust mite, pollen) }\end{array}$ & $\begin{array}{l}\text { Reduced airway hyper-respon- } \\
\text { siveness } \\
\text { Increased IgG2a } \\
\text { Reduced IgE/IgG2a ratio }\end{array}$ \\
\hline Yang et al. & $\begin{array}{l}\text { Peptide immuno- } \\
\text { therapy }\end{array}$ & Subcutaneous & Mouse & Egg & $\begin{array}{l}\text { Protection from anaphylaxis } \\
\text { Decreased histamine } \\
\text { Decreased OVA-specific IgE } \\
\text { Increased IFN- } \gamma \text { (spleen) } \\
\text { Decreased Th2 cytokines } \\
\text { Increased TGF- } \beta \text {, FOXP3 mRNA } \\
\text { (intestine) }\end{array}$ \\
\hline Patriarca et al. & OIT & Oral & Human & $\begin{array}{l}\text { Milk } \\
\text { Egg } \\
\text { Fish } \\
\text { Other }\end{array}$ & $\begin{array}{l}\text { Decreased IgE } \\
\text { Increased IgG4 }\end{array}$ \\
\hline Buchanan et al. & OIT & Oral & Human & Egg & $\begin{array}{l}\text { Increased egg-specific IgG, } \\
\text { IgE unchanged }\end{array}$ \\
\hline Staden et al. & OIT & Oral & Human & $\begin{array}{l}\text { Milk } \\
\text { Egg }\end{array}$ & Decreased IgE \\
\hline $\begin{array}{l}\text { Skripak et al. } \\
\text { Narisety et al. }\end{array}$ & OIT & Oral & Human & Milk & $\begin{array}{l}\text { Decreased PST (IgE mediated) } \\
\text { Increased IgG4 }\end{array}$ \\
\hline
\end{tabular}

Abbreviations: IFN- $\gamma$, interferon- $\gamma$; OIT, oral immunotherapy; OVA, ovalbumin; TGF- $\beta$, transforming growth factor- $\beta$; Th2, T-helper-2; Tregs, regulatory T-cells.

and Ara h-3 by altering single amino acids within immunodominant epitopes. The recombinant protein was expressed in Escherichia coli, which was heat-killed and then administered rectally to $\mathrm{C} 3 \mathrm{H} / \mathrm{HeJ}$ mice. ${ }^{48}$ During a food challenge with peanut 10 weeks later, mice that received the recombinant proteins were protected from anaphylactic symptoms. In mice that received the highest dose of the protein, IL-4, IL-13, IL-5, and IL-10 production was significantly decreased and interferon- $\gamma($ IFN- $\gamma$ ) and transforming growth factor- $\beta$ production was significantly increased. Yang et al. ${ }^{50}$ recently reported results of a study using peptide immunotherapy with immunodominant epitopes of OVA. Mice treated with subcutaneous injections of peptides were protected from anaphylaxis upon OVA challenge, in addition to having decreased serum histamine levels, decreased OVA-specific IgE, reduced Th2 cytokines, and increased IFN- $\gamma$ levels. Furthermore, treated mice had increased levels of mRNA transcripts for Foxp 3 and transforming growth factor- $\beta$ in the intestine, suggesting local immune modulation.

Another novel approach using a herbal formula based on the principles of traditional Chinese medicine (Food Allergy Herbal Formula-FAHF-2) has been effective in oral tolerance induction and protection from anaphylaxis in mouse models of food allergy. ${ }^{51-53}$ Mice receiving FAHF-2 were protected from anaphylaxis for 36 weeks after cessation of therapy, in addition to having reduced peanut-specific IgE and increased IgG2a levels, as well as reduced Th2 cytokine production. ${ }^{53}$ IFN- $\gamma$ production from CD8 + T-cells was significantly increased, and depletion of CD8 + T-cells and IFN- $\gamma$ neutralization decreased the efficacy of FAHF-2. ${ }^{53}$ Additionally, two recent reports describe the use of epicutaneous immunotherapy for treatment of allergic rhinitis in humans ${ }^{54}$ and in mouse models of inhalant and food allergy. 55

\section{Sublingual and oral immunotherapy}

Sublingual immunotherapy (SLIT) and oral immunotherapy (OIT) are two therapeutic modalities of significant interest when exploring interventions to modulate the GI mucosal immune response (Table 2). SLIT involves the use of a liquid concentrate administered under the tongue, whereas OIT involves the use of a powdered food protein administered orally with food. Both modalities have generated significant interest for their ability to induce desensitization, and early work using some 
Table 2 Summary of selected SLIT and OIT studies

\begin{tabular}{|c|c|c|c|}
\hline Investigator & Allergen & Route & Results \\
\hline $\begin{array}{l}\text { Enrique et al.* } \\
\text { ( }{ }^{*} \text { Oral Allergy } \\
\text { Syndrome) }\end{array}$ & Hazelnut & Sublingual & $\begin{array}{l}\text { Increased maximal } \\
\text { threshold dose } \\
\text { Increased IgG4, IL-10 }\end{array}$ \\
\hline $\begin{array}{l}\text { Mempel et al. } \\
\text { Kerzl et al. }\end{array}$ & Kiwi & Sublingual & $\begin{array}{l}\text { Reduced skin test } \\
\text { reactivity } \\
\text { Prolonged desensi- } \\
\text { tization after discon- } \\
\text { tinuation }\end{array}$ \\
\hline $\begin{array}{l}\text { Patriarca } \\
\text { et al. }\end{array}$ & $\begin{array}{l}\text { Milk } \\
\text { Egg } \\
\text { Fish } \\
\text { Other }\end{array}$ & Oral & $\begin{array}{l}\text { Effective desensitiza- } \\
\text { tion }(77 \%) \\
\text { Decreased IgE } \\
\text { Increased IgG4 }\end{array}$ \\
\hline Meglio et al. & Milk & Oral & $\begin{array}{l}\text { Effective desensitiza- } \\
\text { tion }(71 \%) \\
\text { Increased threshold } \\
\text { dose }\end{array}$ \\
\hline $\begin{array}{l}\text { Buchanan } \\
\text { et al. }\end{array}$ & Egg & Oral & $\begin{array}{l}\text { Increased threshold } \\
\text { dose at food chal- } \\
\text { lenge } \\
\text { Increased egg-spe- } \\
\text { cific IgG } \\
\text { No significant change } \\
\text { in IgE }\end{array}$ \\
\hline Staden et al. & $\begin{array}{l}\text { Milk } \\
\text { Egg }\end{array}$ & Oral & $\begin{array}{l}\text { Overall response } \\
64 \% \text { (36\% completely } \\
\text { tolerant of dose) } \\
\text { Increased threshold } \\
\text { dose } \\
\text { Decreased IgE }\end{array}$ \\
\hline Longo et al. & Milk & Oral & $\begin{array}{l}\text { In treatment group: } \\
36 \% \text { completely toler- } \\
\text { ant to milk protein } \\
54 \% \text { consume limited } \\
\text { amounts } \\
\text { 10\% unable to com- } \\
\text { plete protocol } \\
\text { Elimination diet } \\
\text { group: } \\
\text { Positive DBPCFC in } \\
\text { all } 30 \text { subjects }\end{array}$ \\
\hline $\begin{array}{l}\text { Skripak et al. } \\
\text { Narisety et al. }\end{array}$ & Milk & Oral & $\begin{array}{l}\text { Increased threshold } \\
\text { dose } \\
\text { Increased milk-spe- } \\
\text { cific IgG4 } \\
\text { Decreased skin prick } \\
\text { test reactivity }\end{array}$ \\
\hline Jones et al. & Peanut & Oral & $\begin{array}{l}\text { Increased threshold } \\
\text { dose } \\
\text { Decreased PST reac- } \\
\text { tivity } \\
\text { Decreased basophil } \\
\text { activation } \\
\text { Increased IgG4 } \\
\text { Decreased IgE } \\
\text { Increased FOXP3 + } \\
\text { T-cells } \\
\text { T-cell Microarray: } \\
\text { downregulation of } \\
\text { apoptosis genes }\end{array}$ \\
\hline Clark et al. & Peanut & Oral & $\begin{array}{l}\text { Increased threshold } \\
\text { dose }\end{array}$ \\
\hline
\end{tabular}

Abbreviations: IL, interleukin; OIT, oral immunotherapy. models has suggested tolerance induction in patients with food allergy. Both interventions generally involve administering small yet increasing doses of antigen in a controlled setting ("rush" immunotherapy/initial dose escalation phase) followed by regular home dosing during a build-up phase to reach a maximum tolerated maintenance dose of antigen. Treatment is followed by an open or masked food challenge with antigen or placebo to determine clinical desensitization and/or tolerance.

In a study of SLIT for hazelnut allergy, 23 patients received either hazelnut extract or placebo for 8-12 weeks. ${ }^{56}$ In the subsequent food challenge, the mean hazelnut quantity that provoked symptoms increased $9 \mathrm{~g}$ from baseline in the hazelnut group vs. $0.6 \mathrm{~g}$ in the placebo group. Subjects in the hazelnut group also experienced increases in $\mathrm{IgG}_{4}$ and IL-10, although none in the placebo group did. After further analysis it appears that the majority of the patients who benefited from SLIT did not have type-I IgE-mediated allergy, but rather had the oral allergy syndrome/pollen food syndrome, which is characterized by oral itching, tingling, and occasional swelling of the oropharynx in pollen allergic individuals, after consumption of fresh fruits and vegetables containing cross-reactive proteins. SLIT has also been used in a single case for treatment of life-threatening kiwi allergy. ${ }^{57,58}$

\section{Immunotherapy and tolerance induction}

Using a standardized, open OIT protocol for treatment of a variety of different food allergies, Patriarca et al. ${ }^{59}$ reported desensitization in $77 \%$ of subjects. The most common food allergy among subjects was milk, followed by egg and fish. In comparison with age-matched food allergic controls, subjects receiving OIT experienced significant decrease in food-specific $\mathrm{IgE}$ and increase in specific IgG $\mathrm{Ig}_{4}$. Using a 6-month OIT protocol in children with proven IgE-mediated hypersensitivity to milk, Meglio et al. ${ }^{60}$ were able to fully desensitize 15 of 21 children and partially desensitize three children. Even partial desensitization dramatically reduced the risk of severe reactions after unintentional ingestion of small quantities of cow's milk. We have previously reported results from seven subjects with egg allergy who completed a 24-month protocol for egg OIT. ${ }^{61}$ Four of the seven subjects passed a double-blind, placebo-controlled food challenge (DBPCFC) to $10 \mathrm{~g}$ of egg at the conclusion of the therapy, and all subjects tolerated significantly higher doses of egg protein than noted at entry into the study, suggesting effective desensitization to egg protein. Interestingly, another group of investigators evaluated the ability of egg-allergic children to tolerate heated egg protein. Subjects with IgE-mediated egg allergy underwent physician-supervised oral food challenges to extensively heated egg (e.g., muffin or waffle). Subjects tolerating the heated egg protein were then challenged with nonheated egg protein (e.g., scrambled egg, French toast). Subjects tolerating the heated egg protein challenge integrated heated egg into their diets. Heated egg-reactive subjects had larger skin test wheals and elevated egg-specific IgE levels. Continued consumption of heated egg protein in the diet was associated with decreased skin test size, reduced egg-specific IgE levels, and increased IgG4 levels. ${ }^{62}$ 
Whereas both SLIT and OIT have shown promising results, most of the studies reported to date have lacked control groups, and it has been suggested that success of the therapy may be due to spontaneous resolution of the allergies that can occur with age, particularly in milk and egg allergies that are generally "outgrown" in childhood. In a randomized, placebo-controlled study of OIT for cow's milk or egg allergy home daily dosing was conducted until patients ingested either $250 \mathrm{ml}$ milk or $4.5 \mathrm{~g}$ egg protein, which happened after $37-52$ weeks. ${ }^{63}$ Daily dosing was followed by a 2 -month elimination diet and then a double-blind, placebo-controlled food challenge. The results suggested that therapy may not alter the natural course of tolerance development. However, in the tolerance induction group, seven children were considered either partial responders or responders when receiving regular antigen intake, boosting the rate of any response to $64 \%$. Allergen-specific IgE levels decreased significantly in both children who developed natural tolerance during the elimination diet and those who received therapy. Even though partially tolerant patients would need regular intake of allergen to maintain desensitization, this could protect patients against severe reactions or those resulting from accidental exposure to antigen.

A further controlled study of OIT for children with severe allergy to cow's milk found significant differences between those in the treatment group and those who followed an elimination diet. ${ }^{64}$ In the group that maintained an elimination diet, all 30 patients failed a double-blind, placebo-controlled food challenge after 1 year, whereas, $90 \%$ of children in the treatment group could consume between 5-150 ml of milk daily. Half of patients in the treatment group had significant decreases in IgE specific to cow's milk at 6 and 12 months. In the control group, milkspecific IgE levels remained essentially unchanged, and none of the children spontaneously acquired tolerance. Similar results were obtained in another study using OIT for cow's milk allergy, with six of nine subjects reaching the maximal dose of $120 \mathrm{ml}$ of milk with only mild-to-moderate symptoms. ${ }^{65}$

In a recent randomized, double-blind, placebo-controlled study of cow's milk OIT in children, investigators treated 19 children (6-17 years of age) with cow's milk allergy using a desensitization protocol involving a modified rush "build-up day", home dosing with interval observed dose increases up to $500 \mathrm{mg}$, followed by daily maintenance dosing. ${ }^{66}$ Laboratory evaluation of the subjects showed no significant difference in milk-specific IgE levels in the treated vs. untreated groups; however, milk-specific IgG levels, particularly IgG4, were significantly increased. In both groups, the median milk threshold dose inducing allergic symptoms during oral food challenge increased significantly from baseline in the OIT treatment group. These investigators then followed this cohort during an open-label portion of the study to determine the continued safety of milk OIT and the ability of these children to accept increasing doses of milk protein during gradual home dose escalation. ${ }^{67}$ Follow-up oral food challenges were performed on 13 of the subjects, with six tolerating the maximum cumulative dose of $16,000 \mathrm{mg}$ ( $16 \mathrm{oz}$ ) of cow's milk protein without any adverse reaction. The other seven participants tolerated doses ranging from 3,000 to $16,000 \mathrm{mg}$, with symptoms including oral pruritus, abdominal pain, sneezing, cough, and urticaria. Immunologic changes after OIT included significant decreases in end-point titration skin prick testing and milk-specific IgE levels as well as significant increases in milk-specific IgG4 levels. These combined studies show effective desensitization to milk protein while on treatment and the ability to consume increasing doses of milk protein, along with immunologic changes suggesting immune modulation. Further study is needed to assess long-term safety and tolerance induction in this cohort.

\section{OIT for peanut allergy}

Peanut allergy is an increasingly prevalent disorder that is often associated with life-threatening symptoms. In contrast to other allergens such as milk and egg, allergy to peanut is in the majority of cases, a lifelong disorder. Because peanut allergy is rarely outgrown, there is significant interest in development of a definitive therapeutic option. Initial studies of OIT for children with peanut allergy have shown encouraging results. In our study, we evaluated both clinical efficacy and changes in immunologic parameters in children who were treated using an OIT protocol..$^{23}$ Thirty-nine children were initially enrolled and 29 children completed the protocol; 27/29 (93\%) ingested the maximal amount of peanut protein during oral challenge while on OIT. Clark et al. ${ }^{68}$ also reported similar clinical efficacy in four patients who received OIT using a nearly identical dosing protocol. In our cohort, clinical responsiveness was coupled to reduced titrated skin prick test reactivity and decreased basophil activation. ${ }^{23}$ Additionally, in patients undergoing OIT, peanut-specific IgE levels increased initially but then decreased at 12 and 18 months, whereas peanut-specific IgG4 levels increased significantly throughout the study. While on OIT, FOXP3 + Tregs increased 1.5-fold in peanut-stimulated cells at 6 and 12 months on therapy and decreased thereafter, returning to baseline by 20 months. Cytokine secretion was measured in peripheral blood mononuclear cell supernatants after stimulation with concanavalin-A, peanut, Ara h-2, and medium alone and showed that in concanavalin-A-stimulated cells, significant increases in IL-5, IL-10, IFN- $\gamma$, tumor necrosis factor- $\alpha$, and G-CSF were noted in subjects while on OIT, with a significant decrease in IL-2 noted. When crude peanut extract was incubated with the peripheral blood mononuclear cells, significant increases in the levels of inflammatory cytokines and growth factors, such as IL-1 $\beta$, IL-5, tumor necrosis factor- $\alpha$, macrophage inflammatory protein- $1 \beta$, granulocyte colony stimulating factor and granulocyte macrophage colony-stimulating factor, were noted. T-cell microarray data showed downregulation of genes in apoptotic pathways in subjects while on OIT, a novel finding that demands further investigation (Figure 1). In a companion report, Hofmann et al. ${ }^{69}$ examined the safety of OIT during the initial escalation day, build-up phase, and during maintenance home dosing. Allergic reactions were more frequent on the initial escalation day and 20/28 patients received some form of treatment, most commonly diphenhydramine (50\%), with $4 / 28$ subjects receiving epinephrine in combination with either diphenhydramine 
or albuterol. After the initial dose escalation day, the likelihood of allergic reactions decreased significantly during the buildup and home dosing phases; however, two subjects received epinephrine on one occasion each during home dosing. A follow-up report further examined adverse reactions during peanut OIT home dosing and defined five circumstances associated with increased risk of reaction with home dosing, including concurrent illness, poorly controlled asthma, physical exertion after dose administration, timing of dosing after food ingestion, and dosing during menses. ${ }^{70}$ These patterns will inform the design of appropriate safety strategies in future immunotherapy trials.

In addition to focusing on clinical safety in the design of future mucosal immunotherapy trials, investigators should also be cognizant of psychological factors that influence parental decisions to enroll these studies. Dunngalvin et al. ${ }^{71}$ recently reported that parents of children with food allergy who elected to enroll in immunotherapy trials perceived a significantly higher likelihood of their child having a severe reaction or dying if a food was ingested (OR 6.753). Participation in immunotherapy trials could be predicted with $90 \%$ accuracy using this model, reminding investigators that measures must be used to avoid inadvertent coercion in high-risk families.

In summary, OIT appears to be a safe, well-tolerated treatment when performed by experienced personnel in highly supervised research settings with appropriate safety precautions in place. Early studies suggest effective desensitization and modulation of the mucosal response toward tolerance. However future studies are needed to define the mechanisms of oral tolerance induction during OIT, with particular interest in the newly described apoptosis pathways. ${ }^{23}$ Due to the high risk of systemic reactions these therapies are not ready for broad implementation in clinical practice settings at this time.

\section{PREVENTION OF FOOD ALLERGY: IS EARLY ALLERGEN AVOIDANCE THE BEST STRATEGY?}

The prevalence of food allergies is increasing in industrialized countries, with the prevalence of peanut allergy, specifically, trebling in the United Kingdom (0.5-1\% from 1989 to $1994-96$ and $1.8 \%$ in 2003); $; 2,73$ estimates from the United States suggest the prevalence has doubled from 0.4 to $0.8 \%$ between 1997-2002. ${ }^{74}$ Although the data were inconclusive, the United Kingdom Committee on Toxicity (COT) and the American Academy of Pediatrics (AAP) subsequently recommended early dietary restriction of peanuts in what was perceived at the time as a rational strategy to avoid sensitization. ${ }^{75,76}$ However, recent work by investigators in the United Kingdom has challenged this paradigm and resulted in modification of the initial recommendations for early peanut avoidance. ${ }^{77,78}$ Induction of tolerance in infants and toddlers may be important for preventing the development of food allergies. Interestingly, children in countries that have peanut snacks that are safe for infants to consume have relatively low rates of peanut allergies. ${ }^{77} \mathrm{Du}$ Toit $^{78}$ showed that despite apparent earlier introduction of peanut protein into their diet, Jewish children in Israel had a 10-fold lower prevalence of peanut allergy when compared with children of similar genetic background in the United Kingdom ( $0.17 \%$ in Israel vs. $1.85 \%$ in the United Kingdom).

\section{Non-mucosal routes of sensitization}

This same group of investigators examined the effect of lowdose cutaneous sensitization on the development of subsequent peanut allergy. ${ }^{79}$ They hypothesized that because a majority of children have adverse reactions upon their first known ingestion of peanut, alternative routes of sensitization may account for the breakdown in oral tolerance induction. Parents of children referred to a food allergy clinic for evaluation of eczema completed questionnaires regarding peanut intake before parental knowledge of peanut allergic status. Investigators determined that there was a dose-response relationship between household peanut exposure and development of peanut allergy, with median weekly household peanut consumption significantly elevated compared with non-allergic children and high-risk controls with egg allergy.

Existing animal studies support the concept that non-mucosal exposure to food allergens can prevent or disrupt normal acquisition of tolerance. Disruption of the protective outer layer of the skin promotes enhanced allergic sensitization to topically applied food allergens. ${ }^{80,81}$ Mice exposed to peanut through intact and especially through abraded skin before they were fed peanut for the first time could not be made orally tolerant and a Th2 skewed phenotype was evident in peripheral lymph nodes and blood. ${ }^{82}$

Collectively, these observational human studies and experimental animal studies suggest that avoidance of food allergen exposure prevents proper oral tolerance induction and increases the risk of sensitization through cutaneous exposure. Genetic studies of atopic dermatitis populations show a strong effect of fillagrin mutations with up to $48 \%$ of affected individuals carrying null mutations of fillagrin. ${ }^{83}$ Epicutaneous exposure to food allergens results in enhanced allergen sensitization in carriers of homozygous fillagrin mutation in a spontaneous mouse model of atopic dermatitis (the flaky tail mouse).$^{84}$ It is an attractive hypothesis to say that atopic dermatitis and food allergy are so strongly linked in infancy because early transcutaneous exposure to food impairs normal acquisition of tolerance, especially if the food allergen is not consumed orally early in life (before transcutaneous exposure) ${ }^{85}$ However it is difficult to prove cause rather than association. A randomized, controlled trial (Learning Early About Peanut Allergy Study, www.leapstudy. co.uk) is in progress to evaluate whether high doses of peanut protein in high-risk infants are more effective at preventing peanut allergy than avoidance. At present, the idea of early allergen intake to modulate the development of food allergy is an intriguing hypothesis, but further evidence is required to apply this principle to broader clinical practice.

\section{Complementary feeding practices}

The timing of introduction of complementary foods, the foods added to an infant's diet when transitioning from breastfeeding to solid foods, has been a subject of significant interest with regard to primary prevention strategies for atopic disease. 
The German Infant Nutrition Intervention Program (GINI) followed a cohort of 4753 children prospectively for 4 years and determined that neither the timing nor the diversity of complementary foods introduced had any association with development of eczema, even in high-risk families. ${ }^{86} \mathrm{~A}$ second study followed a longitudinal cohort of 642 children and found that later introduction of foods did not have a protective effect on the development of asthma or atopic disease ${ }^{87}$ Concluding that there was insufficient evidence to support avoidance or delay of complementary food introduction, the 2008 recommendations from both the AAP and the European Society for Pediatric Gastroenterology, Hepatology, and Nutrition (ESPGHAN) have been modified. ${ }^{88,89}$ The revised 2008 AAP guidelines do not recommend restriction of maternal diet during pregnancy or breastfeeding, or restriction of allergenic foods in infants after 4-6 months of age. ${ }^{88}$ Similarly, the updated ESPGHAN guidelines state that complementary foods should be introduced after 17 weeks and no later than 26 weeks. ${ }^{89}$

\section{CONCLUSION}

The advent of therapies targeting the mucosal immune response represents substantial progress toward a definitive treatment option for patients with food allergy. However, there are still many unanswered questions about the role of mucosal tolerance in food allergy, including the role of primary prevention strategies, natural history of the disorder, and the role of maternal diet during pregnancy and lactation, as well as the role of food allergen exposure in infants and toddlers in subsequent development of oral tolerance. Further work is necessary to develop improved understanding of the GI mucosal immune response and the mechanisms of oral tolerance induction in order to develop rational treatment strategies and identify novel therapeutic targets to improve the care and quality of life of patients with food allergy.

\section{DISCLOSURE}

Dr Burks serves as a consultant for ActoGeniX, Intelliject, Novartis, and McNeill Nutritionals. He is a Minority Stockholder in Allertein and Mast Cell Inc. He serves on the Advisory Board for Dannon Co.Probiotics and the Expert Panel for Nutricia. Dr Burks has received grant funding from the National Institutes of Health, Food Allergy and Anaphylaxis Network, Food Allergy Initiative, SHA, National Peanut Board, and Wallace Foundation. Dr Scurlock has received funding from the National Institutes of Health/National Institute for Allergy and Infectious Diseases.

(C) 2010 Society for Mucosal Immunology

\section{REFERENCES}

1. Altschul, A.S., Scherrer, D.L., Munoz-Furlong, A. \& Sicherer, S.H. Manufacturing and labeling issues for commercial products: relevance to food allergy. J. Allergy Clin. Immunol. 108, 468 (2001).

2. Joshi, P., Mofidi, S. \& Sicherer, S.H. Interpretation of commercial food ingredient labels by parents of food-allergic children. J. Allergy Clin. Immunol. 109, 1019-1021 (2002).

3. Sicherer, S.H., Burks, A.W. \& Sampson, H.A. Clinical features of acute allergic reactions to peanut and tree nuts in children. Pediatrics 102, e6 (1998).

4. Bock, S.A., Munoz-Furlong, A. \& Sampson, H.A. Further fatalities caused by anaphylactic reactions to food, 2001-2006. J. Allergy Clin. Immunol. 119, 1016-1018 (2007).
5. Clark, S. et al. Multicenter study of emergency department visits for food allergies. J. Allergy Clin. Immunol. 113, 347-352 (2004).

6. Bollinger, M.E. et al. The impact of food allergy on the daily activities of children and their families. Ann. Allergy Asthma Immunol. 96, 415-421 (2006).

7. DunnGalvin, A., de BlokFlokstra, B.M.J., Burks, A.W., Dubois, E.J. \& Hourihane, J.O'B. Food allergy QoL questionnaire for children aged 0-12 years: content, construct, and cross-cultural validity. Clin. Exp. Allergy 38, 977-988 (2008).

8. King, R.M., Knibb, R.C. \& Hourihane, J.O'B. Impact of peanut allergy on quality of life, stress and anxiety in the family. Allergy 64, 461-468 (2009).

9. Cohen, B.L., Noone, S., Munoz-Furlong, A. \& Sicherer, S.H. Development of a questionnaire to measure quality of life in families with a child with food allergy. J. Allergy Clin. Immunol. 114, 1159-1163 (2004).

10. Sicherer, S.H., Noone, S.A. \& Munoz-Furlong, A. The impact of childhood food allergy on quality of life. Ann. Allergy Asthma Immunol. 87, 461-464 (2001).

11. Beyer, K. et al. Human milk-specific mucosal lymphocytes of the gastrointestinal tract display a TH2 cytokine profile. J. Allergy Clin. Immunol. 109, 707-713 (2002).

12. Curotto de Lafaille, M.A. et al. Adaptive Foxp3+ regulatory T cell-dependent and -independent control of allergic inflammation. Immunity 29, 114-126 (2008).

13. Karlsson, M.R., Rugtveit, J. \& Brandtzaeg, P. Allergen-responsive $\mathrm{CD} 4+\mathrm{CD} 25+$ regulatory T cells in children who have outgrown cow's milk allergy. J. Exp. Med. 199, 1679-1688 (2004).

14. Shreffler, W.G., Wanich, N., Moloney, M., Nowak-Wegrzyn, A. \& Sampson, H.A. Association of allergen-specific regulatory T cells with the onset of clinical tolerance to milk protein. J. Allergy Clin. Immunol. 123, 43-52 (2009).

15. da Silva Menezes, J. et al. Stimulation by food proteins plays a critical role in the maturation of the immune system. Int. Immunol. 15, 447-455 (2003).

16. Chase, M.W. Inhibition of experimental drug allergy by prior feeding of the sensitizing agent. Proc. Soc. Exp. Biol. 61, 257-259 (1946).

17. Chehade, M. \& Mayer, L. Oral tolerance and its relation to food hypersensitivities. J. Allergy Clin. Immunol. 115, 3-12 (2005).

18. Friedman, A. \& Weiner, H.L. Induction of anergy or active suppression following oral tolerance is determined by antigen dosage. Proc. Natl. Acad. Sci. USA 91, 6688-6692 (1994).

19. Strobel, S. \& Mowat, A.M. Oral tolerance and allergic responses to food proteins. Curr. Opin. Allergy Clin. Immunol. 6, 207-213 (2006).

20. Worbs, T. et al. Oral tolerance originates in the intestinal immune system and relies on antigen carriage by dendritic cells. J. Exp. Med. 203, 519-527 (2006).

21. Coombes, J.L. et al. A functionally specialized population of mucosal CD103+ DCs induces Foxp3+ regulatory T cells via a TGF- $\backslash\{$ betal\} and retinoic acid dependent mechanism. J. Exp. Med. 204, 1757-1764 (2007).

22. Lack, G. Epidemiologic risks for food allergy. J. Allergy Clin. Immunol. 121, 1331-1336 (2008).

23. Jones, S.M. et al. Clinical efficacy and immune regulation with peanut oral immunotherapy. J. Allergy Clin. Immunol. 124, 292-300 (2009).

24. Fontenot, J.D., Gavin, M.A. \& Rudensky, A.Y. Foxp3 programs the development and function of CD4+CD25+ regulatory T-cells. Nat. Immunol. 4, 330-336 (2003).

25. Hori, S., Nomura, T. \& Sakaguchi, S. Control of regulatory T cell development by the transcription factor Foxp3. (Reports). Science 299, 1057 (2003).

26. Bennett, C.L. et al. The immune dysregulation, polyendocrinopathy, enteropathy, X-linked syndrome (IPEX) is caused by mutations of FOXP3. Nat. Genet. 27, 20-21 (2001).

27. Torgerson, T.R. et al. Severe food allergy as a variant of IPEX Syndrome caused by a deletion in a noncoding region of the FOXP3 gene. Gastroenterology 132, 1705-1717 (2007).

28. Ganeshan, K. et al. Impairing oral tolerance promotes allergy and anaphylaxis: a new murine food allergy model. J. Allergy Clin. Immunol. $123,231-238$ (2009).

29. Blazquez, A.B. \& Berin, M.C. Gastrointestinal dendritic cells promote Th2 skewing via OX4OL. J. Immunol. 180, 4441-4450 (2008).

30. Mayer, L. Mucosal immunity. Pediatrics 111, 1595-1600 (2003).

31. Michael, J.G. The role of digestive enzymes in orally induced immune tolerance. Immunol. Invest. 18, 1049-1054 (1989). 
32. Barone, K.S., Reilly, M.R., Flanagan, M.P. \& Michael, J.G. Abrogation of oral tolerance by feeding encapsulated antigen. Cell. Immunol. 199, 65-72 (2000).

33. Scott, H., Solheim, B.G., Brandtzaeg, P. \& Thorsby, E. HLA-DR-like antigens in the epithelium of the human small intestine. Scand J. Immunol. $12,77-82$ (1980).

34. Groschwitz, K.R. \& Hogan, S.P. Intestinal barrier function: molecular regulation and disease pathogenesis. J. Allergy Clin. Immunol. 124, 3-20 (2009).

35. Ventura, M.T. et al. Intestinal permeability in patients with adverse reactions to food. Dig. Liver Dis. 38, 732-736.

36. Laudat, A., Arnaud, P., Napoly, A. \& Brion, F. The intestinal permeability test applied to the diagnosis of food allergy in paediatrics. West Indian Med. J. 43, 87-88 (1994).

37. Lacaille, F., Laurent, J. \& Bousquet, J. Life-threatening food allergy in a child treated with FK506. [Report]. J. Pediatr. Gastroenterol. Nutr. 25, 228,229 (1997).

38. Granot, E., Yakobovich, E. \& Bardenstein, R. Tacrolimus immunosuppression - an association with asymptomatic eosinophilia and elevated total and specific lgE levels. Pediatr. Transplant. 10, 690-693 (2006)

39. Gabe, S.M. et al. The effect of tacrolimus (FK506) on intestinal barrier function and cellular energy production in humans. Gastroenterology 115 , 67-74 (1998).

40. Boyle, R.J. \& Hardikar, W.T.M. The development of food allergy after liver transplantation. Liver Transpl. 11, 326-330 (2005).

41. Chehade, M. et al. De Novo food allergy after intestinal transplantation: a report of three cases. [Report]. J. Pediatr. Gastroenterol. Nutr. 38, 545-547 (2004).

42. Madsen, K.L., Yanchar, N.L., Sigalet, D.L., Reigel, T. \& Fedorak, R.N. FK506 increases permeability in rat intestine by inhibiting mitochondrial function. Gastroenterology 109, 107-114 (1995).

43. Forbes, E.E. et al. IL-9- and mast cell-mediated intestinal permeability predisposes to oral antigen hypersensitivity. J. Exp. Med. 205, 897-913 (2008).

44. Till, S.J., Francis, J.N., Nouri-Aria, K. \& Durham, S.R. Mechanisms of immunotherapy. J. Allergy Clin. Immunol. 113, 1025-1034 (2004).

45. Francis, J.N. et al. Grass pollen immunotherapy: IL-10 induction and suppression of late responses precedes IgG4 inhibitory antibody activity. J. Allergy Clin. Immunol. 121, 1120-1125 (2008).

46. Oppenheimer, J.J., Nelson, H.S., Bock, S.A., Christensen, F. \& Leung, D.Y. Treatment of peanut allergy with rush immunotherapy 90, 256-262 (1992).

47. Nelson, H.S., Lahr, J., Rule, R., Bock, S.A. \& Leung, D.Y. Treatment of anaphylactic sensitivity to peanuts by immunotherapy with injections of aqueous peanut extract. J. Allergy Clin. Immunol. 99, 744-751 (1997)

48. Li, X.M. et al. Persistent protective effect of heat-killed Escherichia coli producing "engineered," recombinant peanut proteins in a murine model of peanut allergy. J. Allergy Clin. Immunol. 112, 159-167 (2003).

49. Li, X.M. et al. Engineered recombinant peanut protein and heat-killed Listeria monocytogenes coadministration protects against peanut-induced anaphylaxis in a murine model. J. Immunol. 170, 3289-3295 (2003).

50. Yang, M., Yang, C. \& Mine, Y. Multiple T cell epitope peptides suppress allergic responses in an egg allergy mouse model by the elicitation of forkhead box transcription factor 3 - and transforming growth factor- $\beta$ associated mechanisms. Clin. Exp. Allergy 40, 668-678 (2010).

51. Srivastava, K.D. et al. The Chinese herbal medicine formula FAHF-2 completely blocks anaphylactic reactions in a murine model of peanut allergy. J. Allergy Clin. Immunol. 115, 171-178 (2005).

52. Qu, C. et al. Induction of tolerance after establishment of peanut allergy by the food allergy herbal formula-2 is associated with upregulation of interferon-gamma. Clin. Exp. Allergy 37, 846-855 (2007).

53. Srivastava, K.D. et al. Food allergy herbal formula-2 silences peanutinduced anaphylaxis for a prolonged posttreatment period via IFN[gamma]-producing CD8+ T cells. J. Allergy Clin. Immunol. 123, 443-451 (2009).

54. Senti, G. et al. Epicutaneous allergen administration as a novel method of allergen-specific immunotherapy. J. Allergy Clin. Immunol. 124, 997-1002 (2009).

55. Mondoulet, L. et al. Epicutaneous immunotherapy on intact skin using a new delivery system in a murine model of allergy. Clin. Exp. Allergy 40 , 659-667 (2010).
56. Enrique, E. et al. Sublingual immunotherapy for hazelnut food allergy: a randomized, double-blind, placebo-controlled study with a standardized hazelnut extract. J. Allergy Clin. Immunol. 116, 1073-1079 (2005).

57. Mempel, M., Rakoski, J., Ring, J. \& Ollert, M. Severe anaphylaxis to kiwi fruit: immunologic changes related to successful sublingual allergen immunotherapy. J. Allergy Clin. Immunol. 111, 1406-1409 (2003).

58. Kerzl, R., Simonowa, A., Ring, J., Ollert, M. \& Mempel, M. Life-threatening anaphylaxis to kiwi fruit: Protective sublingual allergen immunotherapy effect persists even after discontinuation. J. Allergy Clin. Immunol. 119, 507-508 (2007).

59. Patriarca, G. et al. Oral desensitizing treatment in food allergy: clinical and immunological results. Aliment. Pharmacol. Ther. 17, 459-465 (2003).

60. Meglio, P., Bartone, E., Plantamura, M., Arabito, E. \& Giampietro, P.G. A protocol for oral desensitization in children with IgE-mediated cow's milk allergy. Allergy 59, 980-987 (2004).

61. Buchanan, A.D. et al. Egg oral immunotherapy in nonanaphylactic children with egg allergy. J. Allergy Clin. Immunol. 119, 199-205 (2007).

62. Lemon-Mule, $\mathrm{H}$. et al. Immunologic changes in children with egg allergy ingesting extensively heated egg. J. Allergy Clin. Immunol. 122, 977-983 (2008).

63. Staden, U. et al. Specific oral tolerance induction in food allergy in children: efficacy and clinical patterns of reaction. Allergy 62, 1261-1269 (2007).

64. Longo, G. et al. Specific oral tolerance induction in children with very severe cow's milk-induced reactions. J. Allergy Clin. Immunol. 121, 343-347 (2008).

65. Staden, U. et al. Rush oral immunotherapy in children with persistent cow's milk allergy. J. Allergy Clin. Immunol. 122, 418-419 (2008).

66. Skripak, J.M. et al. A randomized, double-blind, placebo-controlled study of milk oral immunotherapy for cow's milk allergy. J. Allergy Clin. Immunol. 122, 1154-1160 (2008).

67. Narisety, S.D. et al. Open-label maintenance after milk oral immunotherapy for IgE-mediated cow's milk allergy. J. Allergy Clin. Immunol. 124, 610-612 (2009).

68. Clark, A.T. et al. Successful oral tolerance induction in severe peanut allergy. Allergy 64, 1218-1220 (2009).

69. Hofmann, A.M. et al. Safety of a peanut oral immunotherapy protocol in children with peanut allergy. J. Allergy Clin. Immunol. 124, 286-291 (2009).

70. Varshney, P. et al. Adverse reactions during peanut oral immunotherapy home dosing. J. Allergy Clin. Immunol. 124, 1351-1352 (2009).

71. DunnGalvin, A. et al. Profiling families enrolled in food allergy immunotherapy studies. Pediatrics 124, e503-e509 (2009).

72. Grundy, J., Matthews, S., Bateman, B., Dean, T. \& Arshad, S.H. Rising prevalence of allergy to peanut in children: data from 2 sequential cohorts. J. Allergy Clin. Immunol. 110, 784-789 (2002).

73. Hourihane, J.O. et al. The impact of government advice to pregnant mothers regarding peanut avoidance on the prevalence of peanut allergy in United Kingdom children at school entry. J. Allergy Clin. Immunol. 119, 1197-1202 (2007).

74. Sicherer, S.H., Muñoz-Furlong, A. \& Sampson, H.A. Prevalence of peanut and tree nut allergy in the United States determined by means of a random digit dial telephone survey: a 5-year follow-up study. J. Allergy Clin. Immunol. 112, 1203-1207 (2003).

75. Committee on Toxicity. COT report on peanut allergy, http://cot.food.gov. uk/cotreports/cotwgreports/cotpeanutallergy (1998).

76. American Academy of Pediatrics Committee on Nutrition. Hypoallergenic infant formulas. Pediatrics 106, 346-349 (2000).

77. Levy, Y., Broides, A., Segal, N. \& Danon, Y.L. Peanut and tree nut allergy in children: role of peanut snacks in Israel? Allergy 58, 1206-1207 (2003).

78. Du Toit, G. et al. Early consumption of peanuts in infancy is associated with a low prevalence of peanut allergy. J. Allergy Clin. Immunol. 122, 984-991 (2008).

79. Fox, A.T., Sasieni, P., Du Toit, G., Syed, H. \& Lack, G. Household peanut consumption as a risk factor for the development of peanut allergy. J. Allergy Clin. Immunol. 123, 417-423 (2009).

80. Strid, J., Hourihane, J.O'B., Kimber, I., Callard, R. \& Strobel, S. Disruption of the stratum corneum allows potent epicutaneous immunization with protein antigens resulting in a dominant systemic Th2 response. Eur. J. Immunol. 34, 2100-2109 (2004).

81. Hsieh, K.Y., Tsai, C.C., Wu, C.H. \& Lin, R.H. Epicutaneous exposure to protein antigen and food allergy. Clin. Exp. Allergy 33, 1067-1075 (2003). 


\section{REVIEW}

82. Strid, J., Hourihane, J.O’B., Kimber, I., Callard, R. \& Strobel, S. Epicutaneous exposure to peanut protein prevents oral tolerance and enhances allergic sensitization. Clin. Exp. Allergy 35, 757-766 (2005).

83. O'Regan, G.M., Sandilands, A., McLean, W.H.I. \& Irvine, A.D. Filaggrin in atopic dermatitis. J. Allergy Clin. Immunol. 122, 689-693 (2008).

84. Fallon, P.G. et al. A homozygous frameshift mutation in the mouse Flg gene facilitates enhanced percutaneous allergen priming. Nat. Genet. 41, 602-608 (2009).

85. de Benedictis, F.M., et al. \& EPAAC Study Group The allergic sensitization in infants with atopic eczema from different countries. Allergy 64, 295-303 (2009).

86. Filipiak, B. et al. Solid food introduction in relation to eczema: results from a four-year prospective birth cohort study. J. Pediatr. 151, 352-358 (2007).
87. Zutavern, A. et al. Timing of solid food introduction in relation to eczema, asthma, allergic rhinitis, and food and inhalant sensitization at the age of 6 years: results from the prospective birth cohort study LISA. Pediatrics 121, e44-e52 (2008).

88. Greer, F.R., Sicherer, S.H., Burks, A.W. \& the Committee on Nutrition and Section on Allergy and Immunology Effects of early nutritional interventions on the development of atopic disease in infants and children: the role of maternal dietary restriction, breastfeeding, timing of introduction of complementary foods, and hydrolyzed formulas. Pediatrics 121, 183-191 (2008).

89. Agostoni, C., et al. \& ESPGHAN committee on nutrition Complementary feeding: a commentary by the ESPGHAN committee on nutrition. J. Pediatr. Gastroenterol. Nutr. 46, 99-110 (2008). 